\title{
12 Huh? What? - a first survey in twenty-one languages
}

\author{
N. J. Enfield, Mark Dingemanse, Julija Baranova, \\ Joe Blythe, Penelope Brown, Tyko Dirksmeyer, \\ Paul Drew, Simeon Floyd, Sonja Gipper, Rósa S. \\ Gísladóttir, Gertie Hoymann, Kobin H. Kendrick, \\ Stephen C. Levinson, Lilla Magyari, Elizabeth Manrique, \\ Giovanni Rossi, Lila San Roque, and Francisco Torreira
}

\subsection{Introduction}

A comparison of conversation in twenty-one languages from around the world reveals commonalities and differences in the way that people do open-class otherinitiation of repair (Schegloff, Jefferson, and Sacks, 1977; Drew, 1997). We find that speakers of all of the spoken languages in the sample make use of a primary interjection strategy (in English it is Huh?), where the phonetic form of the interjection is strikingly similar across the languages: a monosyllable featuring an open non-back vowel $[a, \mathfrak{x}, \partial, \Lambda]$, often nasalized, usually with rising intonation and sometimes an [h-] onset. We also find that most of the languages have another strategy for open-class other-initiation of repair, namely the use of a question word (usually "what"). Here we find significantly more variation across the languages. The phonetic form of the question word involved is completely different from language to language: e.g., English [wat] versus Cha'palaa [ti] versus Duna [aki]. Furthermore, the grammatical structure in which the repair-initiating question word can or must be expressed varies within and across languages. In this chapter we present data on these two strategies - primary interjections like $H u h$ ? and question words like What? - with discussion of possible reasons for the similarities and differences across the languages. We explore some implications for the notion of repair as a system, in the context of research on the typology of language use.

The text was written by N. J. Enfield and Mark Dingemanse, and benefited from commentary on drafts from all authors. All authors contributed data, transcription and analysis on specific languages (as listed in Table 12.1), and all authors contributed conceptually to the study through participation in project meetings. We thank Paul Kockelman, Jack Sidnell, and Jeff Robinson for comments on earlier drafts, and Galina Bolden for providing Russian data at an early stage of the study. This research was supported by the European Research Council projects "Human Sociality and Systems of Language Use" and "INTERACT" and the Max Planck Institute for Psycholinguistics. 
The general outline of this chapter is as follows. We first discuss repair as a system across languages and then introduce the focus of the chapter: open-class other-initiation of repair. A discussion of the main findings follows, where we identify two alternative strategies in the data: an interjection strategy (Huh?) and a question word strategy (What?). Formal features and possible motivations are discussed for the interjection strategy and the question word strategy in order. A final section discusses bodily behavior including posture, eyebrow movements and eye gaze, both in spoken languages and in a sign language.

\subsection{Repair across languages}

It is hard to imagine how people in a language-using social group could get by without a system for online repair of problems in speaking, hearing, and understanding. "If the organization of talk in interaction supplies the basic infrastructure through which the institutions and social organization of quotidian life are implemented, it had better be pretty reliable, and have ways of getting righted if beset by trouble." (Schegloff, 2006: 77; cf. Schegloff, 1992). Supposing that we do find a system of repair in all languages, many questions arise. In what sense can these be called systems? Are they conventionally linguistic in nature? Do they have emergent properties? Are there differences across human groups? If so, what sorts of factors can account for the differences - cognitive, cultural, communicative? How to determine whether repair is found in all cultural settings, and if it is found in the same form?

One way to approach these questions, following the tradition of systematic comparison of grammatical structure known as linguistic typology, is to build a case from systematic comparison of structures of talk in interaction across a maximally diverse sample. A problem is that, for the kind of data needed, there are no available secondary sources comparable to reference grammars of spoken languages. Grammarians do not describe structures of repair, partly because there is no tradition of such description in linguistics, and partly because linguists have tended not to work with the one kind of data in which these structures can be found: i.e., spontaneous talk in conversational interaction. ${ }^{1}$ The only option is to collect primary data and start afresh. Here we present first findings from a comparative project based on video-recorded everyday conversation in twentyone languages from around the world. ${ }^{2}$ The broad aim is to make a contribution in empirical, methodological, and theoretical terms - to the typology of systems of language use for human interaction.

\subsubsection{Defining other-initiated repair}

Here we focus on a type of other-initiation of repair, ${ }^{3}$ defined as follows. A hearer of a turn at talk has the opportunity to initiate repair of what the prior speaker has just said, through a turn that, firstly, draws attention to a problem of speaking, 
hearing or understanding in the prior turn, and secondly, normatively requires the speaker of that problem-turn to fix the problem. This may be done for example by saying the turn again (for instance if it seemed that there had been a problem of hearing), or by rephrasing it (for instance if it seemed that there had been a problem not of hearing but of understanding). In examples $1 \mathrm{a}$ and $1 \mathrm{~b}$, the target line, highlighted by an arrow, points to a problem (in these cases, of person reference) in the other speaker's prior turn. The problem is addressed by the original speaker in the turn that follows the highlighted turn.

(1a) NBII:1:R:6 (English)

\begin{tabular}{|c|c|c|c|}
\hline & 01 & Lot: & $\mathrm{U}[\mathrm{h}:$. \\
\hline Trouble source & $\begin{array}{l}02 \\
03\end{array}$ & Emm: & $\begin{array}{l}\text { [But PERcy goes with (.) Nixon I'd } \\
\text { sure like tha:t. }\end{array}$ \\
\hline Repair initiation & 04 & Lot: $\rightarrow$ & Who:? \\
\hline Repair & $\begin{array}{l}05 \\
06\end{array}$ & Emm: & $\begin{array}{l}\overline{\text { Percy. }} \\
(0.2)\end{array}$ \\
\hline & 07 & Emm: & That young fella thet uh (.) .hh his \\
\hline & 08 & & daughter wz m: urdered? \\
\hline & 09 & & $(\overline{0.5)}$ \\
\hline & 10 & Lot: & .hhh [OH::: YE::AH:. YE:A[H. y-] \\
\hline & 11 & Emm: & $\begin{array}{l}\text { [They- } \\
\text { [They: }] \text { said }\end{array}$ \\
\hline
\end{tabular}

(1b) Field XI:1:1:1:1 (English)

\begin{tabular}{|c|c|c|c|}
\hline Trouble source & $\begin{array}{l}01 \\
02\end{array}$ & Les: & $\begin{array}{l}\text { Ma:y is: ill too:. She's had eIther a } \\
\text { heart attack or a, slight stro:ke, }\end{array}$ \\
\hline Repair initiation & 03 & Mum: $->$ & Ma:ry? \\
\hline & 04 & & (.) \\
\hline Repair & 05 & Les: & Ma:y. \\
\hline
\end{tabular}

We can schematize this kind of sequence as shown in Figure 12.1.

The critical turn in this three-part structure is "T0," the turn in which it first becomes publicly apparent that there is a problem. Speaker B's turn at T0 (e.g., "Huh?," "What?," "Who?") points back to a problem in Speaker A's prior turn $(\mathrm{T}-1)$, and points forward to a next turn in which Speaker A can repair the problem $(\mathrm{T}+1)$.

\subsubsection{Questions}

We are interested in two interlocking questions for research on other-initiated repair, the first being concerned with the relation between $\mathrm{T} 0$ and $\mathrm{T}-1$, and the second being concerned with the relation between $\mathrm{T}-1$ and $\mathrm{T}+1$.

First: what are the ways in which a person can, at T0, initiate repair by the other speaker of the problem-turn at $\mathrm{T}-1$ ? The defining turn at $\mathrm{T} 0$ can be 
Trouble source

Other-initiation of repair

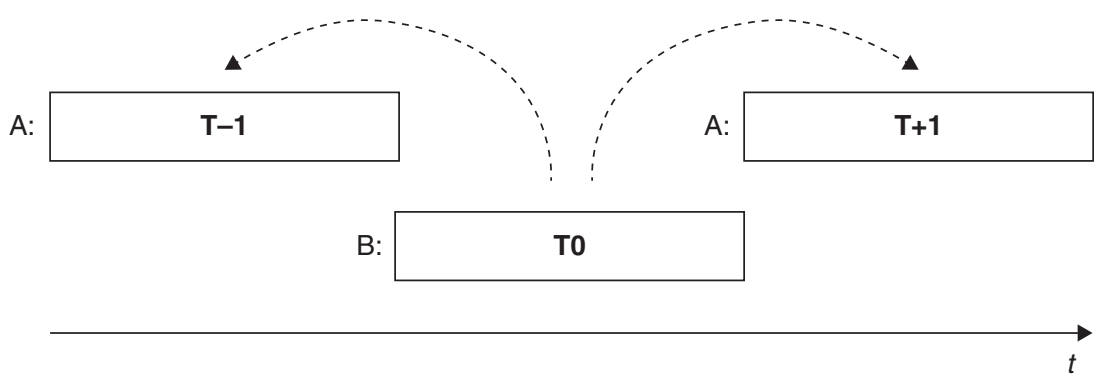

Figure 12.1: The anatomy of other-initiation of repair. Turn 0 points back to a problem in Turn -1 and points forward to a next turn Turn +1 , where the problem can be repaired.

regarded as a structural slot in which a set of non-equivalent strategies can appear. These alternative strategies thus form a system paradigm, from a linguistic point of view; that is, something essentially akin to a paradigm of inflectional morphemes or words of a common form class. Examples 1a and $1 \mathrm{~b}$ show different options for repair-initiation at T0 on a person-referring form in the prior turn: either by using a question word ("Who?" in (1a)), or by repeating one's understanding of what was said, for confirmation ("Mary?" in (1b)). One goal of research here is to describe the formal and functional resources for other-initiation of repair at T0 across languages and cultural settings; another is to look for constraints on that variation.

Second: what are the ways in which a speaker of a problem-turn at $\mathrm{T}-1$ fixes the putative problem at $\mathrm{T}+1$ ? One hypothesis is that the way in which speakers will redo $\mathrm{T}-1$ (e.g., exact repeat versus rewording) is a function of the choice of repair initiator used at T0. Sidnell (2007), working on the Creole language of Bequia, pursues this idea with a focus on person reference, analyzing a set of alternatives for initiating repair (at T0) on a person reference (made in $\mathrm{T}-1$ ). He argues that for three main types of trouble that can occur in person reference problem of hearing, non-uniqueness of a name, and not knowing the person referred to - there are three distinct formats for repair-initiation at T0: "who," "who [NAME]," and "who is named so" (Sidnell, 2007: 307). The issue of how the problem is fixed goes beyond the scope of this chapter (see Section 2.4 below).

Note that there is a third critical question, connected to these two, which we do not systematically address in this chapter: What are the possible kinds of problem that can occur at $\mathrm{T}-1$ ? The space of possibilities is usually defined as "problems of speaking, hearing and understanding" (Schegloff, Jefferson, and Sacks, 1977; Sidnell, 2010). Another way is to appeal to the logic of 
Austin's nested layering of action in language use (Austin, 1962: 94-103); (Clark, 1996: 146). A speech act can be described on different levels simultaneously, and at each of these levels something can go wrong: a person produces noises or visual behavior for another to perceive (where problems will be of articulating and hearing); a person produces linguistic items for another to identify (where problems will be of word selection and recognition); a person has a communicative intention for another to infer (where problems will concern implicature and other "amplicative" interpretation); a person instigates an action for another to take up (where problems will concern appropriateness of response). While it is useful in principle to have this kind of breakdown of the nested layering of action components, when we look at data we find that it is often difficult or impossible to tell in a given instance what the problem actually was (or indeed whether there really was a problem of the kind being indicated), and it is not even in all cases possible to say unequivocally what the putative problem was treated as.

In examples $1 \mathrm{a}$ and $1 \mathrm{~b}$, the relevant practice of other-initiation of repair narrows in on just part of the prior turn. The speakers of the repairinitiating turns (T0, highlighted) are explicit about which part of the prior turn was the trouble source. In these cases, the problem had to do with a person-referring expression (though we note that in example 1 there are two person-referring expressions in T-1; Percy and Nixon). However, it is not necessarily clear to us precisely what the (claimed) problem was; e.g., whether it was a problem of hearing versus a problem of understanding or recognition. Example 1a illustrates that it is also not always clear to the participants, either. The speaker of the original trouble source repairs the utterance first by simply repeating the name she had used before ("Percy"), thus treating it as a hearing problem, only to find that this was insufficient; after a pause in which no uptake comes after the first attempt at repair, she then produces a recognitional reference (cf. Stivers, 2007) to the same person - "That young fella that uh . . . his daughter was murdered?" where the new form also features "try-marking" (i.e., rising intonation as if checking for confirmation of recognition; Sacks and Schegloff, 1979: 18). This secures an explicit claim of recognition in the next turn ("Oh yeah") by the speaker who had initiated repair on the initial use of the referent's name.

\subsubsection{This chapter's focus: open-class other-initiation of repair}

Beyond these kinds of cases, in which a part of the trouble-source turn is focused on, there are practices for "open-class" other-initiation of repair (Drew, 1997). In the open-class type of other-initiation of repair, the form 
used at T0 does not focus on any sub-part of the prior turn as being the source of trouble. Consider some examples (with the T0 turns highlighted with an arrow):

(02) NB IV:5:2 (English)

01 Gla: =An' now I've got (.) tuh wash my hair en get the

02 Tgoop out ' $v$ it'n everything? .hh 'n ah have the

it. $\downarrow$.hhhh $\underline{h} \underline{h}$ $\uparrow$ paypuh here I thought chu might li:ke tịh $\downarrow$ have

Emm: [Th[a:nk yo]u.
Gla:
[En then] you: could retuhrn it ub (.)

个oh along about noㅁ:n,

(0.2)

Emm: $\quad$ Yer goin upp'n ge[tcher hair]: fixxed t]ihda] $\downarrow: y$.

Gla: [befo : re ]h e gets] ho] $\downarrow: m e$.]

$(0.4)$

Gla: $\rightarrow$ What deah[r?

Emm: $\downarrow_{\text {fi }}[$ xed. ]

[Yer goin up tihday'n gitcher hai $\underline{\text { r }}$

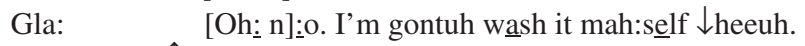

Emm: $\quad$ Oh::.:

Gla: I'm just goi[na sha]mpoo it,=

Emm: $\quad$ [ $\quad$ Oh:. $]$

Gla: $\quad=e n$ then I have some othuh things t' do arou:nd so I

won't be able to u- .hhh $\underline{\text { look }}$ et the paper=

(E): $\quad=[(\mathrm{M})$

Gla: $\quad=[$ 'n ah know you li:ke tuh have it,=

$=. \mathrm{hh}[\mathrm{hh}$

Emm: [个Well [th:a]:nk $\uparrow$ you]=
Gla:
[S $\underline{\mathrm{S}}] \mathrm{u}-\mathrm{e} \mathrm{h}]=$

Emm: $\quad=$ dear ah'll be $\uparrow_{\mathrm{o}: \downarrow_{\mathrm{V}} * \mathrm{er}}$

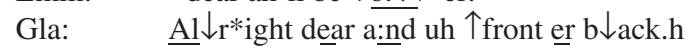

(1.0)

Emm: $\rightarrow$ Wu:t?

(.)

Emm: $\quad \underline{h}[\underline{h} u \underline{h}]$

Gla: [I s][ay f:- $] \quad\left[{ }^{*} \mathrm{u}-\right.$

Emm: $\quad[\underline{\mathrm{OH}}: \ldots: \mathrm{:}]: \mathrm{AH}$ [GUESS th'=

Gla: [ $\quad$ Alsah-].hh]h

Emm:

I look like a wi: ld Indian [cuz] I'm] .hh

[Y $\underline{\mathrm{Ye}}$ a h] 
(03) Holt 1:1:1 (English)

01 Les: m-[Jem's

02 Mum: [Are the family o:ff?

$03 \rightarrow(0.5)$

04 Les: $\rightarrow$ SORRY?

05 Mum: 'Av your family gone o:ff?

06 (.)

07 Les: Ye:s,

08 Mum: $\quad$ Oh $\downarrow_{\text {goo:d, }}$

(04) NB III.2.R*Rev (English)

$01 \quad$ (38.3)

02 Jim: Hello there.

$03 \quad(0.6)$

04 Fra: Hello:

05 Jim: Hello: hello.

$06 \quad(0.4)$

07 Fra: W'ts goin $\underline{\mathrm{o}}:$ n

08 Jim: Not mu:ch. Wuddi[yih know.

09 Fra: $\quad[\underline{\mathrm{Mh}}-$

10 Fra: $\rightarrow$ Huh?

11 Jim: Whuddiyih kno:w.

$12 \quad(0.3)$

Examples (2-4) illustrate what we mean by open-class other-initiation of repair: namely, a practice for drawing attention to a problem in the other's prior turn, without restricting the scope of focus to any component of that turn as being the source of trouble, thereby initiating repair by the other.

\subsubsection{Different strategies}

As the English examples, (2-4) show, different kinds of linguistic formats can function as open-class other-initiators of repair. One basic kind of strategy is to use an interjection such as Huh?, as shown in example 4. Other possible forms of the interjection for this function in English include $h m$ ? and $m m$ ?

Interjections in language are of two types: primary versus secondary (see Bloomfield, 1933: 176). Defined broadly, an interjection is a word unit or equivalent unit that can stand as a complete utterance in itself (e.g., Huh?, Yes, Wow!, No, Yuck; see further discussion, below). A primary interjection is a form that has only this profile. In this way, Huh? can be distinguished from What?. While What? has morphosyntactic combinatoric potential in the language more broadly, Huh? does not. So, in identifying Huh? as the "interjection" strategy, we will always mean it in the sense of "primary interjection" as just defined. 
The second basic strategy for open-class other-initiation of repair is to use a question-word form like What?, illustrated in example 2. This question-word form can also be used for other-initiation of repair in more syntactically elaborate structures such as What's that? and What did you say? By definition, these kinds of structures are distinct from the primary interjection type.

Beyond these two basic strategies - primary interjection and questionword - there are also further ways of doing open-class other-initiation of repair, including Pardon (me)?, Excuse me?, and Sorry? (see example 3). One way to think about the distinctions among these forms is in terms of a contrast of perceived formality or politeness (cf. Huh? versus I beg your pardon?). Another is that the options may differ in terms of specific action nuances. For example, it has been suggested that Sorry? portrays the problem as being the fault of the repair-initiator, not of the speaker of the trouble-source turn (Robinson, 2006).

The strategies in English for carrying the action of open-class otherinitiation of repair in this position (immediately following another speaker's turn containing a trouble source) are non-identical alternatives. The existence of sets of alternatives that can each appear in a single slot is a hallmark of linguistic and other communicative systems. This is why we can speak of systems of language use in the domain of social interaction. Because What? and $H u h$ ? are alternatives for the same slot, it may be that there is a functional distinction between them. One possibility might be that the two formats indicate different types of problems in $\mathrm{T}-1$. For instance, one form might be used when you didn't hear something and the other for when you didn't understand something (though this particular possibility appears not to be supported by data from English; Drew, 1997). Or maybe one form is just more polite than the other. Further research will provide answers to these questions (Drew, 1997: 73); (Robinson, 2006: 142). ${ }^{5}$

If the various alternatives - Huh?, What?, etc. - aren't merely interchangeable, then it is possible that one of them is unmarked relative to the other, in the sense of being a default choice for open-class other-initiation of repair. This would mean that among the possible forms for initiating repair, certain forms would be used for specific purposes (e.g., Sorry? for when you want to do other-initiation of repair and claim responsibility for the problem), and if none of those extra, specific purposes applied, then a default form would be used. This default would be semantically unmarked with reference to the alternatives (i.e., it would have fewer semantic specifications), but it would not necessarily be less frequent. If $H u h$ ? were pragmatically unmarked relative to What?, then Huh? would be the default way of doing other-initiation of repair. The choice of What? would then be less expected, thus signaling, by contrast within a system of alternatives, 
that something special were meant by its selection. Its core semantic meaning would contribute to understanding just what is specially meant by it. This kind of default/marked relation is seen in a whole range of linguistic pragmatic systems, such as systems for person reference (e.g., in English, "first name only" is unmarked relative to "description'; e.g., Where's John? versus Where's His Majesty?; Enfield and Stivers, 2007) or systems for responding to polar questions (e.g., the English system for answering with "type-conforming" interjections like yes versus marked alternatives such as a partial repeat of the question; e.g., A: Is he going? B: He's going; see Raymond, 2003).

To figure out the structure and dynamics of any one language's system for other-initiation of repair would be a major research project in itself, and we do not attempt that here. The aim of this first foray into the comparison of systems for open-class other-initiation of repair is, given that all languages from a broad sample appear to show the same sequential pattern of other-initiation of repair (Figure 12.1, above), to ask whether there is evidence of a basic system-level split between a primary interjection strategy and a question word strategy in the T0 slot. We demonstrate below that a basic Huh?/What? distinction will be found in most if not all languages, though it remains an open question as to what the functional distinction is (e.g., whether the use of "Huh?" versus "What?" can be found to correlate with different repair operations on $\mathrm{T}-1$ that are performed at $\mathrm{T}+1)$.

\subsection{Findings}

Each researcher consulted a corpus of recorded interaction, and collected instances of open-class other-initiation of repair, to find out whether the two general types of strategy - primary interjection versus question word - were used. $^{6}$

Since we are working with a large number of languages - twenty-one languages from six continents; see Table 12.1 - our scope is necessarily restricted. We ask: do all languages show a formal contrast between a primary interjection strategy and a question word strategy for other-initiation of repair? The answer to this question is "almost all languages in our broad sample." Two of the languages examined (Yélî Dnye and Tzeltal) did not yield clear evidence from the available corpora that a question word strategy is used for open-class other-initiation of repair.

A first finding - perhaps trivial but nevertheless deserving of explicit mention here - is that (open-class) other-initiation of repair is observed in all of the languages in our sample, with the sequential organization shown in 
Table 12.1: Approximate phonetic forms used for open-class other-initiation of repair in " $T 0$ " in twenty-one languages.

\begin{tabular}{|c|c|c|c|c|c|}
\hline Language & Affiliation & Location & Research by & Interjection $^{7}$ & $\begin{array}{l}\text { Question } \\
\text { word }\end{array}$ \\
\hline$\neq \overline{\text { Ākhoe Hail lom }}$ & Khoisan & Namibia & Hoymann & he & mati \\
\hline Cha'palaa & Barbacoan & Ecuador & Floyd & $\mathrm{a}:$ & $\mathrm{ti}$ \\
\hline Chintang & Kiranti & Nepal & Dirksmeyer & hã & $\mathrm{t}^{\mathrm{h}} \mathrm{\varepsilon m}$ \\
\hline Duna & Duna-Bogaia & PNG & San Roque & $\tilde{\varepsilon}: / h m$ & aki \\
\hline Dutch & Germanic & Netherlands & Dingemanse & h3 & wat \\
\hline English & Germanic & UK & Drew & hã:/hm & wat \\
\hline French & Romance & France & Torreira & $\tilde{\varepsilon}$ & $\mathrm{k}^{\mathrm{h}} \mathrm{wa}$ \\
\hline Hungarian & Uralic & Hungary & Magyari & hm (ha) & $\mathrm{mi}$ \\
\hline Icelandic & Germanic & Iceland & Gísladóttir & ha: & $\mathrm{k}^{\mathrm{h}} \mathrm{va}: \theta$ \\
\hline Italian & Romance & Italy & Rossi & $\varepsilon:$ & $\mathrm{k}^{\mathrm{h}} \mathrm{oza}$ \\
\hline Kri & Vietic & Laos & Enfield & ha: & tu'?I: \\
\hline Lao & Tai & Laos & Enfield & hã: & i'nay \\
\hline Mandarin Chn. & Sinitic & Taiwan & Kendrick & hã: & รุตวว \\
\hline Murrinh-Patha & Southern Daly & Australia & Blythe & $\mathrm{a}:$ & tangu \\
\hline Russian & Slavic & Russia & Baranova & ha: & to \\
\hline Siwu & Kwa & Ghana & Dingemanse & hã & be: \\
\hline Spanish & Romance & Spain & Torreira & $\mathrm{e}$ & $\mathrm{ke}$ \\
\hline Tzeltal & Mayan & Mexico & Brown & hai & (binti) \\
\hline Yélî Dnye & isolate & PNG & Levinson & $\tilde{\varepsilon}$ & (lukwe) \\
\hline Yurakaré & isolate & Bolivia & Gipper & $\mathfrak{x} / \mathrm{a}$ & tæp $\int æ$ \\
\hline $\mathrm{LSA}^{8}$ & $\begin{array}{l}\text { Deaf sign } \\
\text { language }\end{array}$ & Argentina & Manrique & NA & NA \\
\hline
\end{tabular}

Figure 12.1. In each language, we observe sequences in which people use other-initiation of repair to draw attention to problems, thus eliciting repair of an earlier trouble-source turn. Our main interest here is to examine the kinds of resources used across the languages in T0 position. The results are presented in Table 12.1.

\subsubsection{Primary interjection strategy}

The primary interjection strategy shows remarkable cross-linguistic similarity in phonetic form (see Table 12.1). It is always a monosyllable, typically involving an open front vowel or similar (e.g., $[\mathrm{a}, \mathfrak{x}, \partial, \Lambda]$ ), sometimes with a voiceless $h$ - onset (English huh? [hã:] being a prime example), sometimes with nasalization, and typically done with rising, "questioning" pitch. In addition, it is always a primary interjection, in the sense of Bloomfield (Bloomfield, 1933; Goffman, 1978; Ameka, 1992; Kockelman, 2003). Goffman classified 
interjections as "non-word vocalizations" (1978: 809), stating that "nonwords can't quite be called part of a language" (1978: 810). ${ }^{9}$ Others have likewise suggested that interjections are "nonverbal" (Burling, 1993: 29) and "nonlexical" (Ward, 2006: 129). Contrary to this view, we do not want to call these expressions non-words. They are conventionalized signs that function as items within a linguistic system. They are subject to well-formedness constraints and they need to be learned. Matisoff $(1994: 117,127 \mathrm{n} 8)$ relates how long it took him to learn that Lahu $h a i^{51}$ [hã̂i] is functionally equivalent to American English huh [hã:], because the Lahu form is intonationally different (cf. our discussion of Icelandic and Cha'palaa, below).

Now we present some examples to illustrate the interjection in situ. In an example from Tzeltal (a Mayan language of Mexico), the use of jai [hai] as an other-initiator of repair in line 2 elicits a near-exact repeat of the troublesource turn:

(05) Tzeltal (EX1 T012017 вот50, 12:14:4)

$01 \quad$ A: $\quad$ ya x'obol ba a'pas tatik?

You will do it please sir?

((perform a curing ceremony for patient))

02 B: $\rightarrow$ jai? [hai]

$\rightarrow$ Huh?

03 A: $\quad$ ya bal x'obol ba a'pas tatik?

Will you do it please sir?

04 B: yakuk

Okay.

In an example from Siwu (a Kwa language of Ghana), Speaker $\mathrm{C}$ wonders aloud why a batch of gunpowder is being made, suggesting (by means of a polar question in line 1) that it may be for a funeral. D asks where this supposed funeral is to take place (line 2) - this is followed by over a second of silence before $C$ produces the open-class repair-initiator $h \tilde{a}$ (in line 4). This elicits an exact repeat of the trouble-source turn (line 6).

(06) Siwu (GunPOWDER_1452175)

$01 \mathrm{C}$ : ìde kàku kere tá-màbara kpòkpòkpò-ò?

S.I-be funeral just PROG-3PL-do IDPH.pounding-Q

isn't it for a funeral that the kpòkpòkpò

[pounding] is being done?

02

$\mathrm{D}: \quad \mathrm{Il} \varepsilon$ is $\varepsilon-\varepsilon$ ?

place S.I-sit-Q

where is it?

03

(1.3) 
04

C: $\quad \rightarrow \quad$ hã? [hã:]

repair

huh?

05

(0.3)

06

D:

Ilı̀ is $\mathcal{\varepsilon}-\mathcal{\varepsilon}$ ?

place S.I-sit-Q

where is it?

07

(3.0)

08 C: i Mempeasem ngbe!

loc PSN here

in Mempeasem here!

In an example from Lao (a Tai language of Laos, Thailand, and Cambodia), three women are talking while they prepare to do a recording for the researcher. $\mathrm{R}$ wonders (in line 1) how long the recording will need to be. Either because her way of asking this is vague (not specifying that it is "time" she is asking about), or perhaps because it is a topical discontinuity (Drew, 1997), it results in other-initiation of repair by $\mathrm{L}$ (line 3), which in turn results in R's more specific rewording in line 5 of the trouble-source (line 1).

(07) Lao (LNEPVDP15AUG0503_000304)

01 R: qaw3 thòò1-daj3 naø want extent-indef tpc

How much is required?

$02 \quad$ (0.6)

03 L: $\rightarrow$ haa2? [hã:]

Huh?

$04 \quad(0.2)$

05 R: cak2 naathii2

how.many minute

How many minutes?

$06 \quad$ (2.0)

07 R: kheng1 sua1-moong2 vaa3

half hour qplr.infer

Half an hour?

08 L: han5-dêê4 san4 laaw2 vaa1 kheng1 sua1-moong2

that's-right thus 3 sg say half hour

09

That's right, he said half an hour...

laaw2 vaa1

3 sg say

... he said.

In an example from Murrinh-Patha (a Southern Daly language of Australia), two elderly women are reminiscing. Line 2 is vaguely expressed by Mary, with ellipsis of the thing being spoken about ("trees"); Lily's interjection 
$a a$ in line 5 elicits specification of this ellipsed material by Mary in line 6 , which in turn elicits Lily's demonstration of understanding at line 7.

(08) Murrinh-Patha (Little Trees, 20091121JBvID03_1043611)

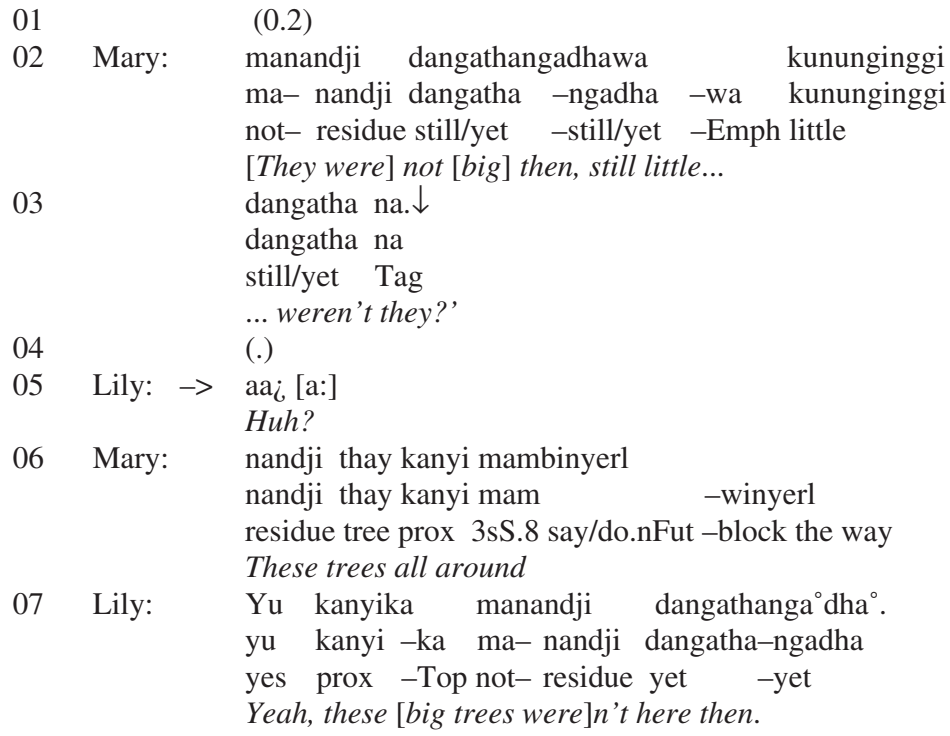

In an example from Yurakaré (a language isolate of Bolivia), $\mathrm{M}$ and $\mathrm{A}$ are talking about a laptop computer that is being used in field work. $\mathrm{M}$ asks $\mathrm{A}$ in line 1 whether it does not have enough power at the moment. In line 3, A initiates repair with the interjection $\ddot{e}$, after which M repeats her utterance in line 4.

(9) Yurakaré (270807_conv)

$01 \mathrm{M}:$ tishi nij da lacha? tishilë nij da lacha now NEG give.SP too It doesn't have enough energy now either?

$02 \quad$ (.)

03 A: $\rightarrow \quad$ ë?=æ

INTJ

Huh?

$04 \mathrm{M}: \quad=$ nij da layj tishilë nij da lacha tishilë NEG give.SP too now It doesn't have enough energy right now either? 
05

06

A:

nijta

NEG

It doesn't.

In an example from Dutch (a Germanic language spoken in the Netherlands), $\mathrm{B}$ initiates repair with the interjection $h 3$ ? (line 3 ). This elicits a near-identical repeat of the trouble source turn in line 4, leaving off only "dispensable" material that tied it to the larger sequence (Schegloff, 2004).

(10) Dutch (Femmie-Richard_566791)

01 A: ja hier [voor het spoor nog hè, hier-? yes here before the tracks still TAG here

B: $\quad$ [oh ja. ] yeah here before the tracks actually right? Here-

oh yes

oh yes. ((shifts gaza to A))

$03 \rightarrow$ he? [h3]

huh?

04 A: hier voor het spoor nog. here before the tracks still here before the tracks.

And finally, in this case from Yélî Dnye (a language isolate spoken on Rossel Island in Papua New Guinea), two men are making arrangements concerning various debts. The interjection in line 2 elicits an exact repeat (in line 3 ) of the problem turn (line 1).

(11) Yélî Dnye (R03_v19_s2 13:56)

01 I: n:uu ye ngmepe?

Who 3Pl.DAT repay

Who is repaying them?

$02 \mathrm{~K}: \quad \rightarrow \quad$ :êê $[\widetilde{\varepsilon}]$

Huh?

03 I: n:uu ye ngmepe

Who 3Pl.DAT repay

Who is repaying them?

04 K: kî pini dy:eemi knî

That man.Spec with.brother.inlaw dual

That man with brothers in law

We also observed a non-open-mouth variant of the primary interjection in a number of the languages. In an example from Duna (a Trans New Guinea 
language spoken in Papua New Guinea), four women (Julinda, Keti, Weselin, and Weli) and two boys (Kelo and Kelson) are sitting preparing food. Julinda is relating who attended a social event at her house earlier in the week (lines 2-3). Apparently prompted by Kelo's interjection at line 5, she partially repeats her problem-turn as line 6 .

(12) Duna (2010-08-07 DV17.2)

01

02 Jul: Mindipi-ne apoko\#o:\#> Wili-ne kheno

Mindipi-PR whatsit Wili-PR 3d

Mindipi and what's-his-name, and Wili...

03

$04 \quad(0.6)$

05 Klo: $\rightarrow$ hmm?

06 Jul: (Mindipi Wi[li-ne ((inaud.)))?]

Mindipe Wili-PR

Mindipi and Wili ((inaudible))

07 Wel: sondopa-ne-[ngi, sondopa-ne-(ngi)]

four-ORD-TIME four-ORD-TIME

On Thursday, on Thursday.

08 Kls: $\quad \begin{array}{ccccc}\text { [ Asde yupela } & \text { (wa]ts) } & ( & \text { ) } & a\end{array}$

Did you guys (watch a movie) yesterday?

09 Klo: ((looks away from Jul, possibly in direction of

$M / W$ 's house $)$ )

$10 \quad$ ((returns gaze to Julinda $))$

$11 \quad$ (1.1)

12 Jul: Mindipi Wili-ne kheno ko-na.

Mindipi Wili-PR 3d be/stand/make.PFV-SPEC

I said Mindipi and Wili!

13 Klo: $\quad($ (eyebrow flash to Julinda $))$

14 Jul: ((?nods))

15 Wel: sondopa-ne-ngi ra-ngi=pe.

four-ORD-TIME SHRD-TIME=Q

On Thursday, was it then?

16 Jul: ((turns head away from Kelo, to her front))

$17 \quad(1.5)$

In an example from Hungarian, two university students are having a conversation by means of a telephone-like setup with headphones when one of them (Beáta) hears a knock through her headphones. She reacts with surprise (in line 8), wondering aloud what it was. Andrea initiates repair in line 10. 
(13) Hungarian (ANDREA-BEÁTA 364.63S)

01 And: tehát érdekes volt legalább valakinek thus interesting was "at least" someone-Dat thus it was interesting at least someone ... tetszett $=$ like-Past

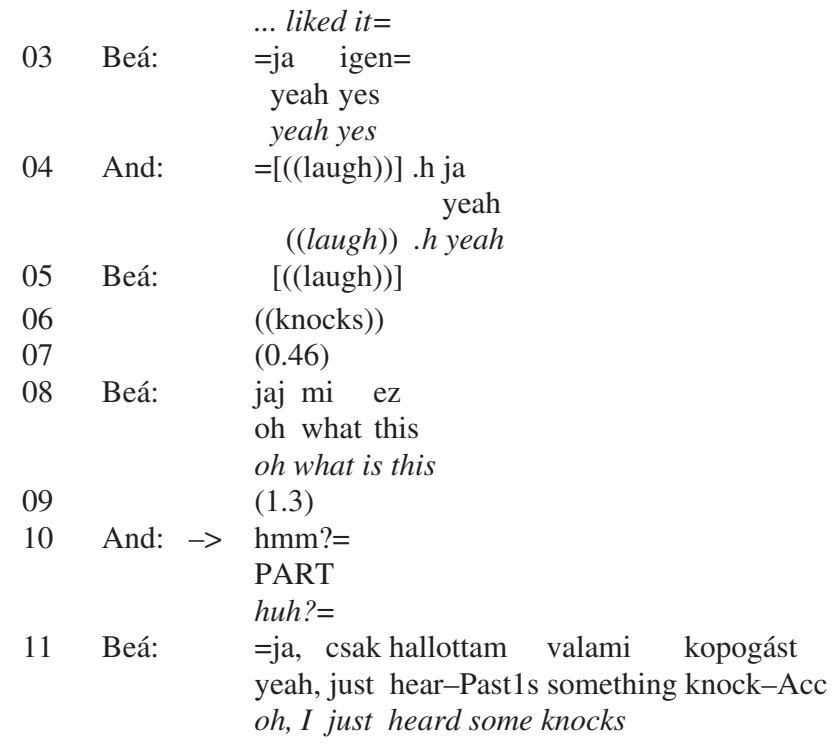

\subsubsection{Possible motivations for form of interjection}

Why are the interjection forms listed in Table 12.1 so close to each other in form despite the unrelatedness of these languages? ${ }^{10}$ Why do we not see an interjection for open-class other-initiation of repair that features high vowels like [i] or [u]? Or with segmental onsets like [b], [t] or [j]? We can only presume that there is some kind of indexical-iconic motivation that makes the sound [ha: + RISING PITCH] appropriate for this function. While human language is unique in many ways, it is not exempt from the forces of ritualization that can shape form-function relations in any form of animal communication.

Darwin (1872) proposed three principles by which expressive behavior in animals can come to have meaning: (1) a principle of function (behavior associated with some function comes to stand for that function); (2) a principle of antithesis (behavior that maximally contrasts in form with a "functional" signal comes to stand for the opposite function); (3) a principle of direct response (behavior that is a direct response of the nervous system to some kind of input) (Darwin, 1872: 166). ${ }^{11}$ While Darwin was mostly referring 
to visible behaviors of the body such as posture and facial expression, his principles are more broadly applicable. We now discuss some ways in which Darwin's principles could go some way to explaining what we find in the case of the other-repair-initiating interjections.

\subsubsection{Motivation for form of the interjection by a principle of function?}

In illustrating his first principle of ritualization of expression, Darwin hypothesized, for example, that feelings of disgust are linked with "serviceable" (i.e., functional) gestures of revulsion, such as blowing air out of the mouth or nostrils, with the tongue protruding. He noted that the wideopen mouth and guttural sounds commonly found in interjections of disgust fit these gestures (Darwin, 1872; Wierzbicka, 1991: 313-316). Could interjections with conversational functions such as the ones considered here be approached using a similar logic? One argument might be that the form of huh? [ha:] is connected to a common bodily behavior we observe accompanying other-initiated repair in our sample: an accelerated leaning forward of the torso toward the speaker of the trouble-source turn, as illustrated in Figure 12.2.

One result of this behavior of bringing oneself physically closer to someone is to be better able to hear and see what the person is saying. If this visual signal were to be accompanied by a vocal signal, perhaps a leasteffort form would be [hã], as initiation of articulatory airflow is assisted by the leaning forward (which compresses the lungs) and phonation is simply frication at the narrowest place in the vocal tract followed by voicing, all articulators are in neutral position. Nasalization of the interjection, also found in many of the languages, may be connected to the fact that, for reasons of articulatory ease, syllables with initial $h$ - are commonly nasalized (Matisoff, 1975; Blevins and Garrett, 1992). While this hypothesis for a natural motivation for the form of huh? is not inconceivable, it is hard to imagine how it could be tested.

We can also apply Darwin's principle of function in motivating the common (though not universal) rising of pitch in these repair-initiating interjections. Gussenhoven (2004) describes the "frequency code" (Ohala 1983 ; 1984), a semiotic principle based on the size of the articulatory apparatus, "and by extension, on the size of the creature that possesses it" (Gussenhoven, 2004: 94). This principle is "widely used for the expression of affective meanings," where low pitch is associated with a physically larger signer and therefore with "masculinity, dominance/assertiveness, confidence, and protectiveness"; correspondingly, high pitch is associated with "femininity, submissiveness/friendliness, insecurity, and vulnerability." The connection between high pitch and uncertainty is widely regarded as a motivating factor for the association of rising pitch with "questioning." 
(a)

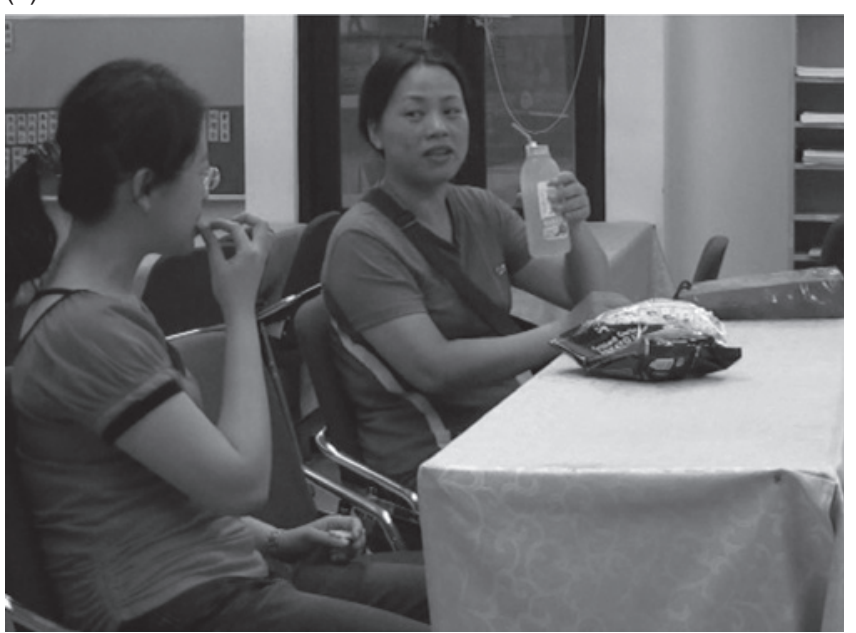

(b)

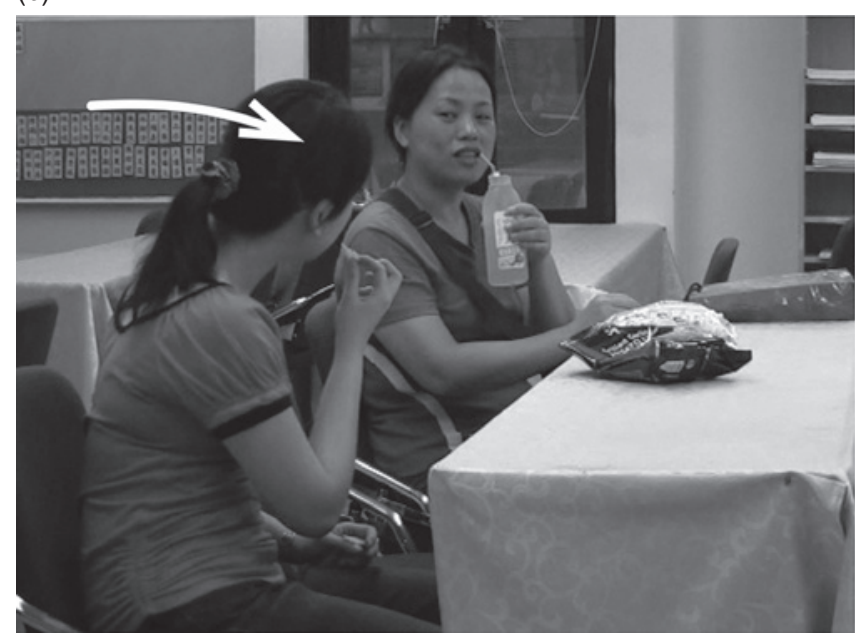

Figure 12.2: Mandarin speakers (Taiwan): the speaker on the right utters a problem-source turn at T-1 (left frame); then the speaker on the left initiates repair with $h m$ ? as she moves her body sharply forward, also tilting her head toward the speaker of $\mathrm{T}-1$ (right frame) (TPE 15). 
(a) Mandarin [hã:]
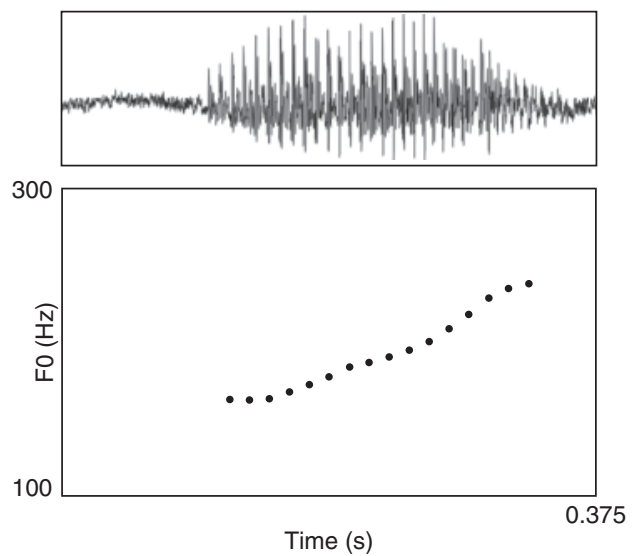

(b) Siwu $\left[{ }^{\mathrm{h}} \mathrm{e}\right]$ or [? e]
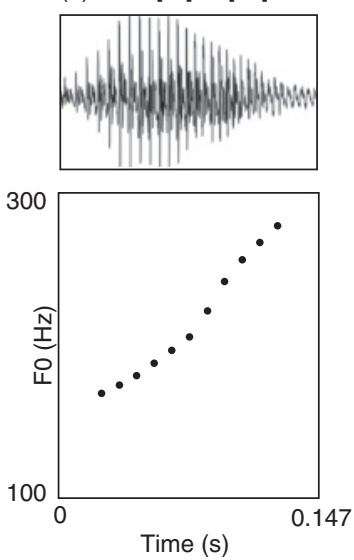

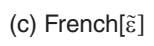

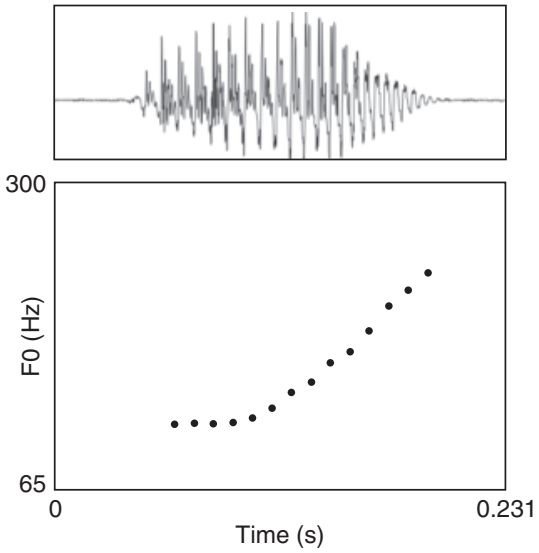

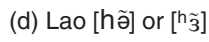
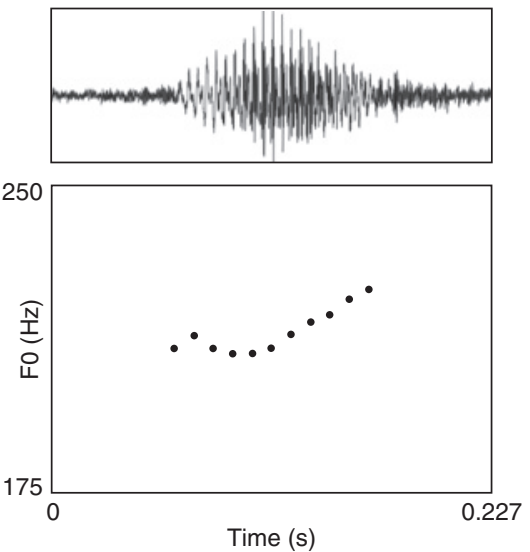

Figure 12.3: Pitch contours for typical tokens of the interjection strategy for other-initiation of repair in four languages: Mandarin, Siwu, French, and Lao.

Accordingly, the $h u h$-interjection is generally rising in pitch in the languages in our sample, as illustrated by the examples given in Figure 12.3.

Two languages in our sample are exceptions to the tendency for huh? to have rising pitch: Icelandic and Cha'palaa. Let us take the Icelandic case as an example. In Icelandic, the open-class other-initiator of repair $h a$ is pronounced with falling tone. A typical example is the OIR sequence in (14). 
(14) Icelandic (ÍS-TAL: 04 ... 07 (11:56))

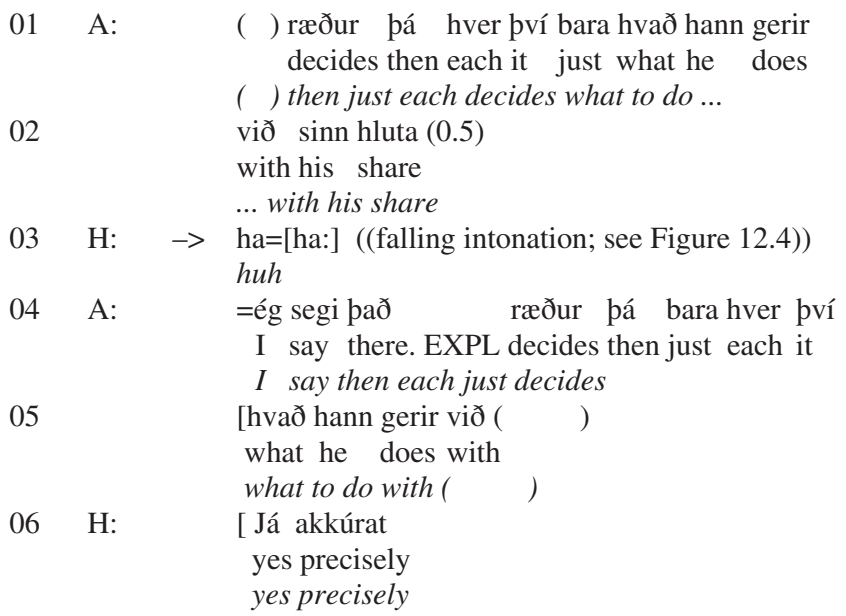

A falling intonation on the interjection for other-initiation of repair may sound counter-intuitive to many non-native ears, but it is consistent with the internal organization of the Icelandic system of pitch in questioning. Although there is considerable variation in question intonation in Icelandic, the preferred nuclear question contour in WH-questions and yes/ no-questions is a falling bitonal pitch accent followed by a low boundary tone, $\mathrm{H}^{*} \mathrm{~L} \mathrm{~L} \%$ (Dehé, 2009). The low boundary tone is typically used at the end of utterances (both declaratives and questions) to mark finality (Árnason, 1998; Dehé, 2009). ${ }^{12}$ It is therefore not surprising that one can request information in Icelandic using the interjection $h a$ with falling intonation.

In all of the Icelandic cases we examined, the pitch of $h a$ was falling in this way. We observed the same in the data from Cha'palaa, where the pitch of $h a$ is also falling (though we have less certainty about the conventional use of pitch in the questioning system more generally). Figure 12.4 shows pitch contours for typical tokens of the interjections in Icelandic and Cha'palaa. Aside from these two languages in our sample, we have found one similar case reported in the literature: in Lahu, a Tibeto-Burman language of mainland Southeast Asia, the Huh? word has falling pitch (Matisoff 1994). So, while we see in our sample a common natural motivation for the rising pitch contour, we also find exceptions, illustrating how conventionalization and interaction with other subsystems - such as question prosody - can attenuate the forces of iconic-indexical motivation in a linguistic system. Further work will establish the nature of the connections between prosodic conventions and the other-initiation of repair. 
(e) Icelandic [ha:]
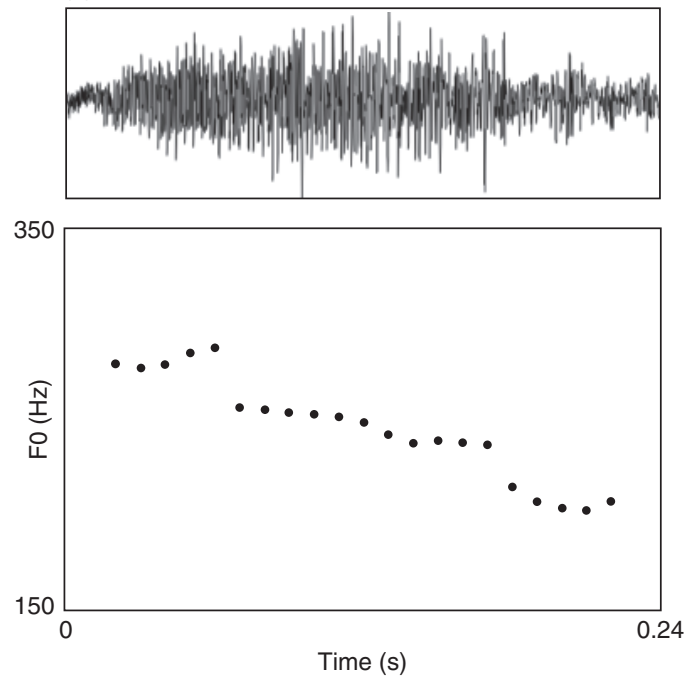

(f) Cha'palaa [â]
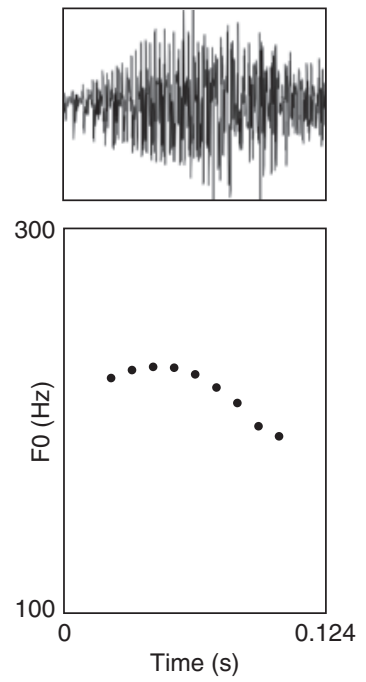

Figure 12.4: Pitch contours for typical tokens of the interjection strategy for other-initiation of repair in two languages: Icelandic and Cha'palaa.

\subsubsection{Motivation for form of the interjection by a principle of antithesis?}

Darwin's second principle by which expressions of emotion and related inner states may become fixed is a principle of antithesis: a bodily behavior can be a natural sign based not on what it is, but on what it contrasts with. Darwin (1872: 14-15) gives the example of how a dog signals affection. Darwin firstly notes the visible features of a dog in a "hostile frame of mind" upright, stiff posture, head forward, tail erect and rigid, bristling hairs, ears forward, fixed stare - suggesting that these behaviors are intelligible by his first principle of function, that is, in that they "follow from the dog's intention to attack." With these behaviors positively associated with the aggressive meaning, he argues, the dog may exploit this to express the opposite of aggression by simply "reversing his whole bearing," that is, doing the opposite of what one would do when aggressive. Thus, when approaching his master in an "affectionate" attitude, visible behaviors include: body down, "flexuous movements," head up, lowered wagging tail, smooth hair, ears loosely back, loose hanging lips, eyes relaxed. Darwin wrote:

None of [these] movements so clearly expressive of affection, is of the least direct service to the animal. They are explicable, as far as I can see, solely from being in complete opposition to the attitude and movements which are assumed when a dog intends to fight, and which consequently are expressive of anger. (Darwin 1872: 15-16). 
Table 12.2: Some formal and functional contrasts between Huh? and Oh!

\begin{tabular}{lll}
\hline \hline & Huh? & Oh! \\
\hline vowel & low front & high back \\
rounding & unrounded & rounded \\
pitch contour & rising & falling \\
sequential position & initiating & responsive/closing \\
epistemic value & not-knowing & now-knowing \\
\hline \hline
\end{tabular}

What, then, might Huh? maximally contrast with in form (and function)? A possibility is another common primary interjection with interactional function: Oh! (Heritage 1984; 1998; 2002; Wierzbicka 1991: 325). Supposing that $O h$ ! is as cross-linguistically common as $H u h$ ?, could it be that these two simple conversationally procedural interjections get their meaning through a diagrammatic iconicity by which a maximal formal contrast in phonetic form (vowel quality, lip rounding) stands for a maximal functional contrast in interactional function (sequential position, epistemic value)? Consider Table 12.2.

If an opposition between Huh? and $O h$ ! were to be motivated by Darwin's principle of antithesis alone, then it would explain the maximal distinction in form for these two functions, but it would not explain why the other-initiation of repair function would always map onto a [ha:]-like form rather than an [o:]-like form. But even somewhat weak functional motivations for those forms to have just those functions, in combination with the principle of antithesis, would presumably suffice to result in the form-meaning mappings that we observe.

12.3.2.3 Summary Naturally any ritualization arguments for formmeaning mappings like those just presented must remain tentative. Nevertheless, we submit that factors like effort, articulatory phonetics, bodily gestures, and systemic contrast should play a role in explaining phonetic similarities of interjection forms across languages, as in the striking case of Huh? across languages. For linguistic items like the interjections discussed here, these natural factors are overlaid by language-specific conventions. Sapir recognized this when he proposed that interjections, though linked historically to "instinctive cries," are fully conventional and "differ widely in various languages in accordance with the specific phonetic genius of each of these" (1921: 4). ${ }^{13}$ As this chapter shows, the forms may differ less than widely. But in line with Sapir we would expect to see in interjection systems not pure natural meaning, but some attenuation of those forces due to the "specific phonetic genius" of individual language 
systems, and in general, the socially mediated nature of conventionalized interjections.

\subsubsection{Question word strategy}

The question word strategy for open-class other-initiation of repair shows much more variation across the languages not only in the phonetic form of the key lexical item (as is readily seen in the rightmost column of Table 12.1). Variation is also observable in whether the word may be used alone (as in the case of English What?), whether it may be phonetically reduced (English Wha'?), whether it is necessarily or more usually embedded in a more complex structure (such as in the Chintang form themkha "what + EMPHATIC PARTICLE" or the Icelandic form hvað segirðu/sagðirðu "What do/did you say?"), which question word is used (e.g., "what" versus "how"), or indeed whether the language does not seem to make this strategy available at all. We now discuss these different patterns of question word use in open-class otherinitiated repair.

12.3.3.1 Bare question word "what" In some languages, the question word "what" can be used all by itself as an open-class other-initiator of repair (e.g., What? in English, as we saw in example 3). This question word tends to be the one also used for "things." In an excerpt from Cha'palaa (a Barbacoan language of Ecuador), a man tells his daughter (walking from off camera into the shot) not to walk in such a way that the floor vibrates, because it might cause the camera on the tripod to move. The daughter answers with the word $t i$ ("what"), which then elicits a full repetition of the negative imperative form (with the addition of a reason for the admonition). ${ }^{14}$ After the repetition $\mathrm{H}$ goes on to elaborate his negative imperative with a declarative clarification "It could fall."

Cha'palaa (CHSF2011-01011S2 1:34-1:38)

$01 \quad \mathrm{H}: \quad$ pikish -ne -tyu mama tremble-walk-neg mama Don't walk vibrating "mama" Don't make the floor vibrate, daughter.

$02 \quad$ (.)

$03 \mathrm{~N}: \rightarrow \mathrm{ti}$

$04 \quad \mathrm{H}: \quad$ pikish - ne -tyu (.) tya'pu-mi tremble-walk-neg (.) fall.over-decl Don't walk vibrating (.) it falls.

Don't make the floor vibrate (.) the camera could fall. 
Here is a case from Mandarin (drawn from a recording of Beijing Mandarin). Friends are discussing each other's email addresses to determine whose is the coolest.

(16) Mandarin (CMC01)

01 Wan: haishi wo de zui ku. or 1SG PRT most cool

02 Zha: ni de jiao sha? 2SG PRT call what what's yours?

03 Wan: in my eyes. ((in English)) in my eyes.

04 Zha: $\rightarrow$ shenme?

what

what?

05 Wan: in my eyes a. heh

PRT

in my eyes. heh

06 Nin: duo ku a. shi bijiao ku. much cool PRT COP relatively cool Very cool. It's cooler.

And here is an example from French:

(17) French (Torreira 27-11-07_2_F13R_2298)

01 A: Je pense pas qu'elle avait dit que les carreaux I think not that.she had said that the tiles I don't think she said that the tiles

02 allaient mieux went better looked better.'

03 B: $\rightarrow$ Quoi?

What?

04 A: Je pense pas qu'elle avait dit que les carreaux I think not that.she had said that the tiles I don't think she said that the tiles allaient mieux went better looked better.'

12.3.3.2 Abbreviated forms Some of the languages show a shortening or abbreviation of the "what" word in the function of other-initiation of repair. In an example from Kri (a Vietic language spoken in Laos), the usual word for




(18) Kri (050719D; 26.58)

$01 \quad$ M: $\quad$ khanờờ qôông côlq nờờ

still Mr. C qplr.agree

There's still Mr. Côlq, right?

$02 \mathrm{~L}: \quad \rightarrow$ q $\mathbf{e} \hat{\mathbf{e}}$ ?

What? ((short for tuqềे $))$

$03 \mathrm{M}$ : coo-qiin qơr qôông côlq nờờ

really-say still Mr. C qplr.agree

(I) said there's still Mr. Côlq, right?

In an example from Russian, shto "what" occurs as chio:

(19) Russian (20110813_School_Friends_b_180010)

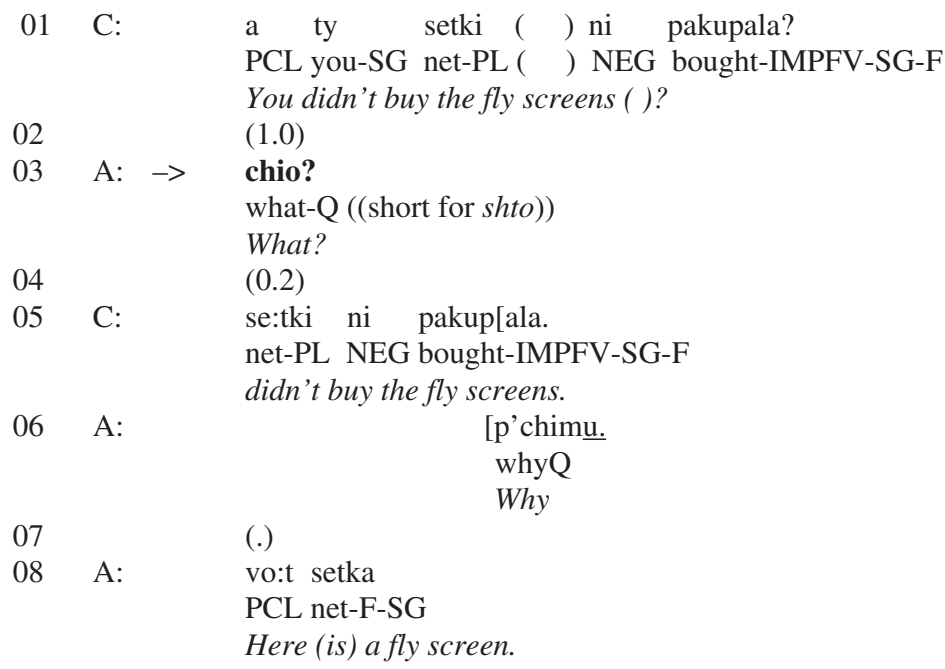

12.3.3.3 More complex forms In other languages, the question word occurs together with further material (either optionally or obligatorily).

In Icelandic, hvað "what" (neuter, singular, nominative/accusative form of hver "who") is used in open-class other-initiated repair as an element of the expression hvað segirðu, "What do you say" (often articulatorily reduced, as [k $\mathrm{k}^{\mathrm{h}}$ vasejIry]), or hvað sagðirðu "What did you say." Hvað cannot appear on its own as an open-class repair initiator (which may be partly explained by the fact that hvað usually only refers to neuter singular referents in nominative or accusative case). ${ }^{15}$ The following example shows hvað segirðu combined with the open-class repair initiator $h a$. In the example, Halldóra is telling her friend Anna about a man who invited a woman she knows to a 
confirmation celebration at very short notice. Halldóra's speech becomes unclear due to laughter, which triggers Anna's repair initiation at line 5.

(20) Icelandic (ÍS-TAL:04 ...07 (00:05:40))

$01 \quad$ H: $\quad$..pá um kvöldið sko then in evening-the well

$04 \quad$ ((laughs $(1.2)))$

05 A: $\rightarrow$ ((laughs) $)$ ha hvað segirðu huh what say you

$06 \quad \mathrm{H}: \quad$ hegar hun wat do you say? ... then in the evening... fermingardagskvöldið pá hafði hann confirmation-day-evening-the then had he ... the evening of confirmation then he had ... hringt í pau (0.5) og ((laughs)) og boðið beim called to them and and invited them ... called them and, and invited them

\begin{tabular}{|c|c|c|}
\hline & & $\begin{array}{l}\text { when she Ragnheiður was confirmed } \\
\text { when Ragnheiður was confirmed }\end{array}$ \\
\hline 07 & A: & já \\
\hline 08 & H: & yes pá hringdi hann (0.9) sem sagt (0.5) að kvöldi \\
\hline 09 & & $\begin{array}{l}\text { he called in the evening ... } \\
\text { fermingardagsins } \\
\text { confirmation-day-the.GEN } \\
\text {... of the confirmation }\end{array}$ \\
\hline
\end{tabular}

In Italian, we see two distinct forms for "what" - che and cosa - occurring as an idiomatic combination. In example 22, Amerigo is talking to Giacinta about his friendship with Elisabetta (who is also present). The repair initiation is due to the fact that Giacinta doesn't catch Amerigo's word play with Elisabetta's name in line 2. In line 3 Giacinta seems to be using a continuer (from off-camera) to invite Amerigo to go ahead with his telling, and without showing any reaction to Amerigo's joking speech. Amerigo tries to resume his telling in lines 5 and 7. However, both Elisabetta's laughter in line 4 and Amerigo's smile-voice in 5 possibly make Giacinta realize that something happened in the prior turn which she didn't get, and she initiates repair in line 6 . Her repetition of the pun in line 11 displays her appreciation of it, following Elisabetta's repair in line 8 .

(21) Italian (Amerigo1:00.56.14)

01 Ame: da quando:: il nos-il rapporto fra from when the our the relationship between since:: ou-the relationship between ... me:: e l'ebilasetta: è cresciuto:? me and the ebilasetta is grown ... me.: and Ebilasetta: has grow:n? 


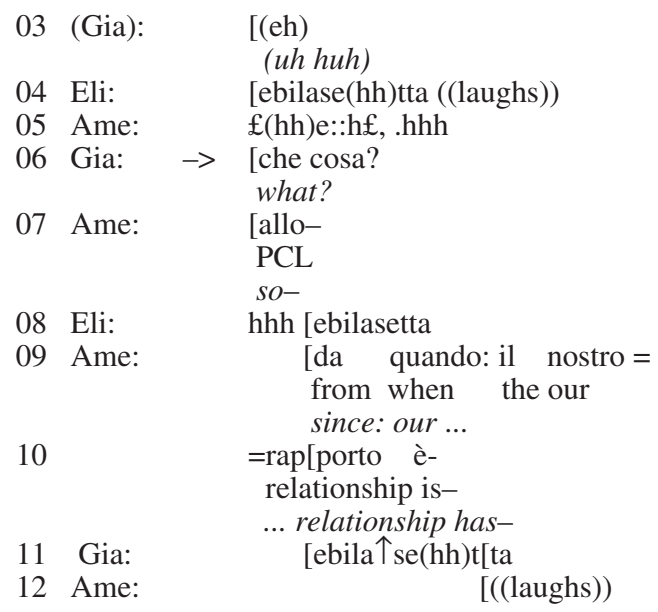

In Chintang (a Tibeto-Burman language of Nepal), them "what" often occurs in combination with a special "emphasis" marker, =kha. In example 22, a group of villagers have been talking, when BSR - who has been silent for a long time - poses a question that is completely unrelated to the current sequence. This is received with an open-class other-initiation of repair from KBR (line 3), after which BSR asks the same question again, in reordered form (line 4).

(22) Chintang (PORCH_POSTMAN (00:32:07 - 00:32:13)

01 BSR: [moba sa]lo chace yuyno ?

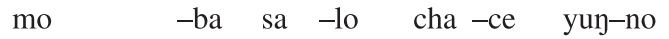

DEM.DOWN-LOC who-NOM child-NSG sit-NPST

down who children is?

Up there, is that the children there?

((points upwards, with hold on yuyno; after salo, KBR

$02 \quad(0.3)$

turns his head to face BSR)) $)^{16}$

03 KBR: $\rightarrow$ them(k)ha

them=kha

what $=\mathrm{EMPH}$

what?

What?

04 BSR: chace uyunno, mo[ba]

cha -ce u -yun -no mo -ba

child-NSG 3ns-sit -NPST DEM.DOWN-LOC

(the) children are, down?

Are the children there, up there?

((repeats point))

05 KBR:

\author{
[ee] chace \\ ee cha -ce \\ INTERJ child-NSG \\ yes children \\ Yes, the children.
}


In many of the languages the "what" word can optionally occur as one element of more substantial expressions: examples are Siwu fo so be "you said what?" and English What's that? or What did you say? The existence of these more complex forms suggests a derivational relation between the single word strategy ("what?") and the more complex phrase ("What did you say?").

12.3.3.4 Question words other than "what" While the question word that is used for open-class other-initiation of repair tends to be the one also used for "things," we note that in some languages a question word meaning "how" can also be used (cf. English How do you mean?). Here is an example from Spanish.

(23) Spanish (Torreira 23_23LM_461)

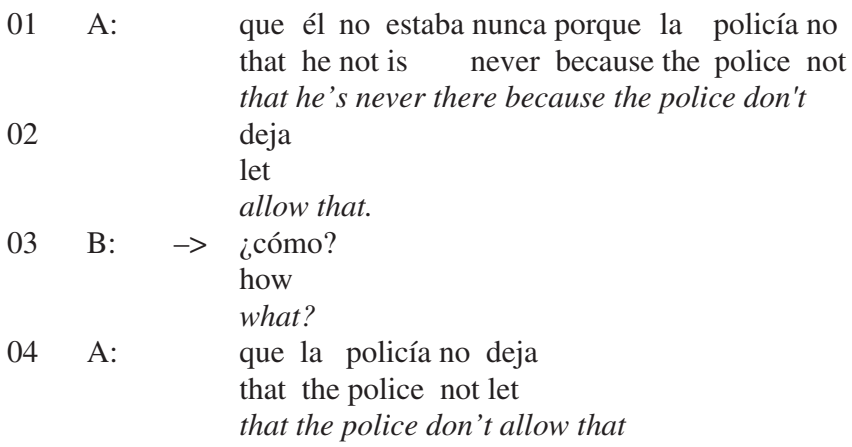

Here is an example from $\neq \bar{A}$ khoe Hai ||om (a Khoisan language of Namibia):

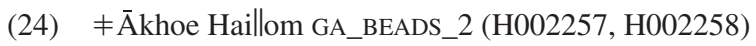

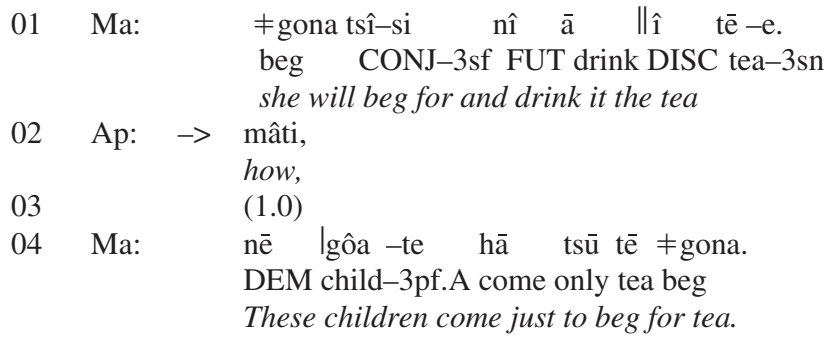

In the languages in our sample, if a "how" word is available for the function of open-class other-initiation of repair, then the "what" word will also be available for that function. 
12.3.3.5 Languages with no question word strategy? For two languages in our sample, the available data do not yield examples in which the question word strategy is used for open-class other-initiation of repair. These are Tzeltal, spoken in Mexico, and Yélî Dnye, spoken in island Papua New Guinea. This is not to say that the languages lack a question word for "what" (see Brown, 2010; Levinson, 2010 on the question systems of these languages). Rather, when the relevant "what" word is used in other-initiation of repair, it is to initiate restricted-focus repair, that is, it asks "what thing (did you mean)?" It remains to be seen whether further data collection may turn up cases of a question word functioning to initiate open-class repair in these languages. Our impression for many of the languages sampled here is that the question word strategy for "open-class" repair is less frequent than the interjection strategy. ${ }^{17}$

12.3.3.6 Summary We have seen in this section that there is considerable variation in the ways in which a question word can be used for "open-class" other-initiation of repair. One issue for us was whether a question word can be used for this function at all. We found that the answer seems usually to be "yes," but that this question word strategy appears to be less frequently used for this function than the interjection equivalent. For two languages in the sample we found no occurrences at all of a content word for open-class other-initiation of repair. A second question was the identity of the relevant question word: in most cases, it is "what?'; that is, the word for questioning "things." In a few cases, another question word may also be used, such as "how?", but this seems to be an additional option when "what?" is also available. A third question was whether the question word could be used all on its own, or whether it is embedded in a larger structure, for instance with certain morphosyntactic marking, or in a complete sentence. We found languages in which some morphosyntactic marking is obligatory (as in Icelandic) and also languages in which the question word may appear on its own but also optionally in more complex morphosyntactic structures (as in English: What did you say?).

\subsubsection{Visible behavior in sign language and spoken language}

The relevance of visible behaviors for the management of intersubjectivity in conversation is well established (Kendon, 1967; Goodwin, 1981; Rossano, Brown, and Levinson, 2008, inter alia). Goodwin has described how speakers can use self-repair to secure a recipient's gaze. The converse, the use of visible behaviors in other-initiation of repair, has been less commonly considered (but see Seo and Koshik, 2010). In our data, common visible behaviors associated with other-initiation of repair are (1) eyebrow movements (raising and/or bringing together), (2) gaze towards the speaker of $\mathrm{T}-1$, and (3) head or body movement toward the speaker of $\mathrm{T}-1$, as discussed above (Figure 12.2). Each of these behaviors is relevant to other-initiation of repair 
in its own way. Eyebrow movements commonly occur with questions in spoken as well as signed languages (Ekman, 1979; de Vos, van der Kooij, and Crasborn, 2009), recipient gaze is often used as a display of attention, and body movement toward the speaker improves perceptual access.

There is one language in our sample - Argentine Sign Language or LSA - that relies on the manual-visual channel entirely. As a sign language, LSA does not feature vocal forms as listed in Table 12.1, but its strategies for other-initiation of repair are nevertheless similar to what we find in the spoken languages in our sample. Firstly, we observe in LSA the same sequential structure for other-initiation of repair (both open-class and restricted-focus) as outlined in Figure 12.1. The strategies for open-class other-initiation of repair at T0 in LSA involve conventionalized eyebrow movements, hand signs such as "what," and movements of the head and/or body toward the signer of the problem turn.

In example 25, illustrated in Figures 12.5 and 12.6, two friends are chatting over dinner about places to live in Buenos Aires Province. Signer A (left), after multiple checks for signer B's attention, resumes a previous sequence in line 4 by asking a question (line 4 and Figure 12.5). However, B is looking down during the production of this turn. In the next turn, B initiates repair by raising his eyebrows (Figure 12.6, glossed as "ER" in line 5), then bringing them together and making the sign "wait" (Figure 12.7, glossed as "ET + wait" in line 5). As is evident from Figure 12.5, the problem is one of seeing, and accordingly, A treats it as such at line 6 , when he fixes the problem by repeating the utterance and filling in the ellipsis.

(25) LSA (PIZZA 1.12)

01 A: ((looks at B while B is eating))

$02 \quad(0.3)$

03 A: ((looks at B while B is looking in other direction))

04 A: $\quad \frac{\mathrm{q}}{\text { PRO1 SAY-NOT PRO3 PRO1 }} \frac{\mathrm{q}}{\text { [PUs+ER:: }}$

I am not going to tell them, right?

B: $\quad \rightarrow$

[ER ET+WAIT::=

Ah wait, huh?

06 A: $\quad=$ PRO1 SAY-NO [PRO3 PALM-UP TAKE-CARE THIEVES

I am not going to tell them, you take care there are thieves (in the neighborhood where his friend is going to move)

B:

$[\mathrm{PU}$

Sure.

In the spoken languages in our sample, we also observed that certain visible behaviors were associated with other-initiation of repair. These behaviors are similar to the strategies used in LSA: leaning forward toward the speaker of 


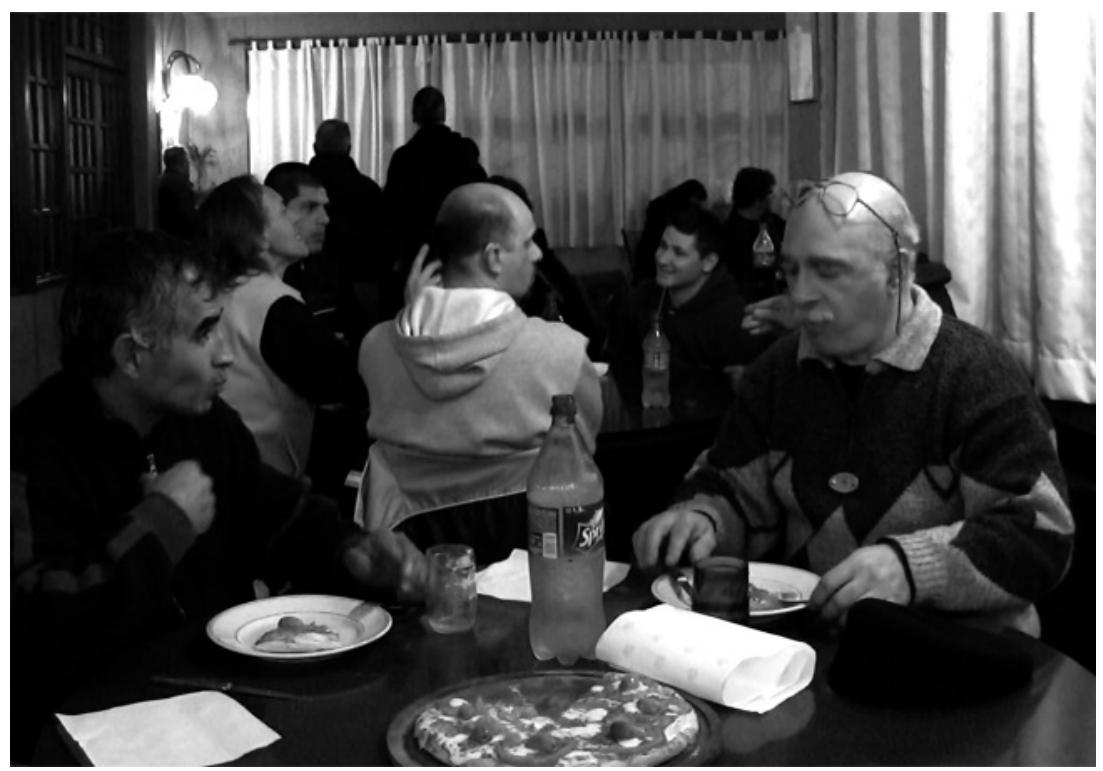

Figure 12.5: At line 4, A requests B's confirmation (see example 25).

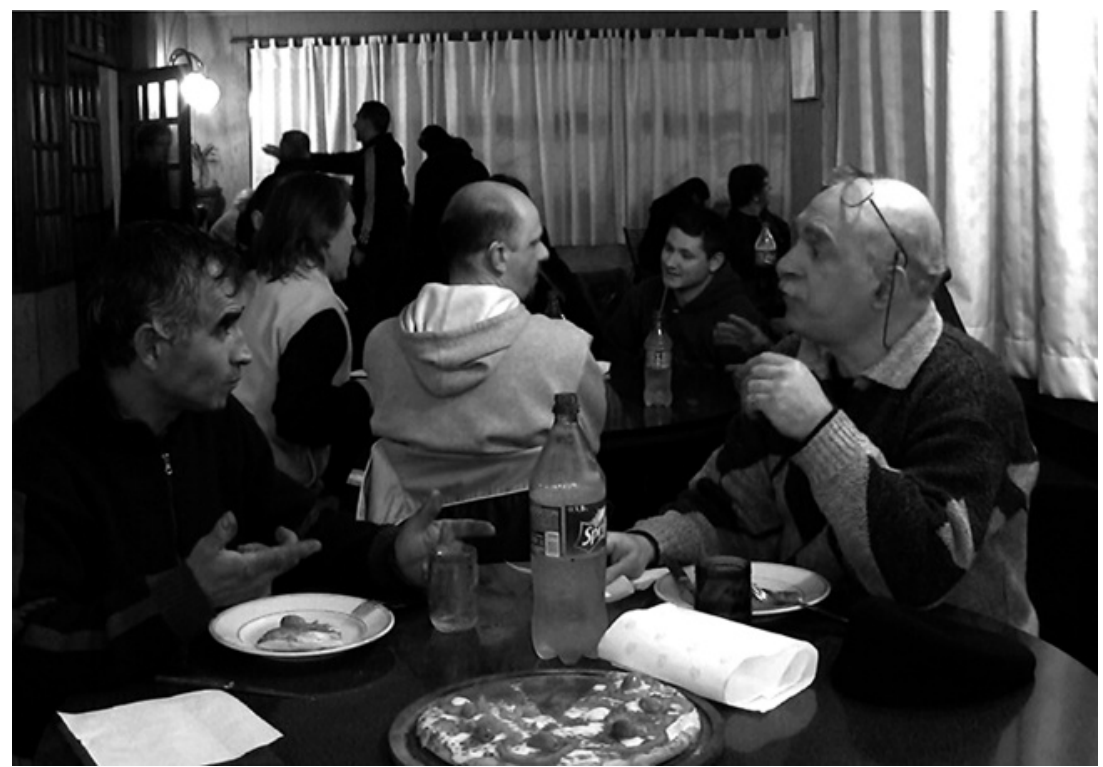

Figure 12.6: At the start of line 5, B initiates repair on A's prior turn by raising his eyebrows as a first indication of a problem (see example 25). 


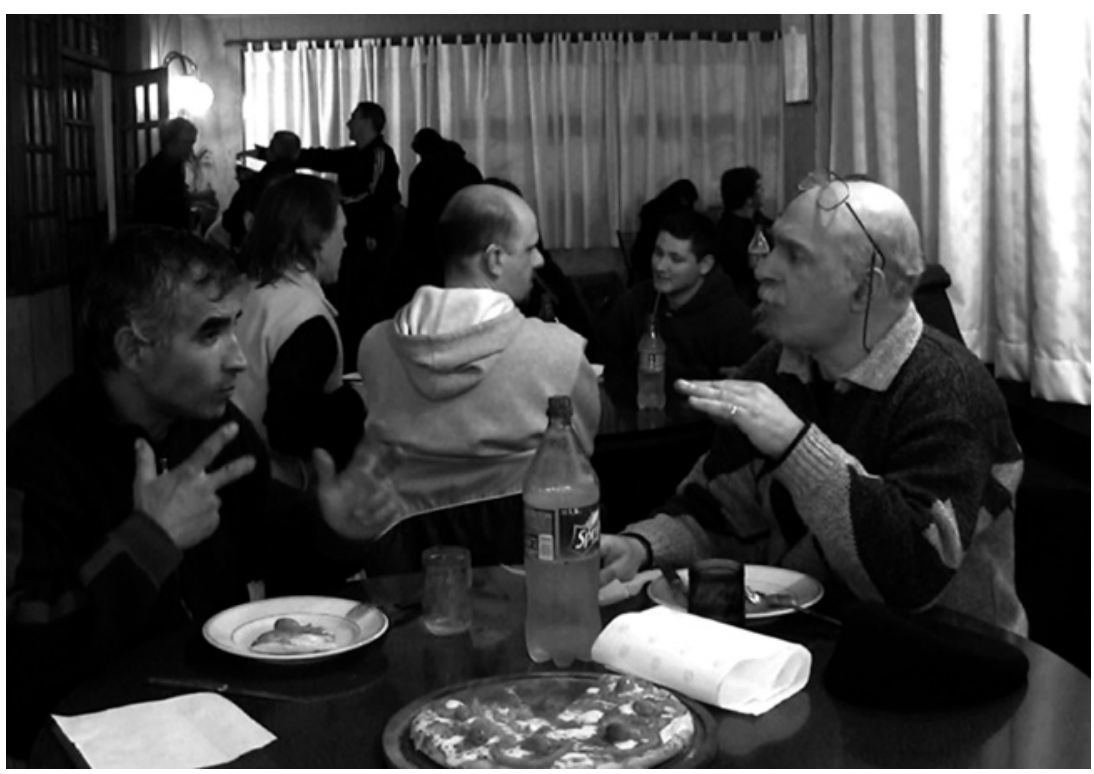

Figure 12.7: Immediately after this, B initiates open-class repair by bringing his eyebrows together and signing "WAIT" (see example 25).

the problem turn in order to get physically and thus perceptually closer (illustrated by a case from Mandarin in Figure 12.2, p. 360 above); using certain facial expressions including marked positioning of the eyebrows (raised in some cases, drawn together in others).

The visible behaviors that we find to be associated with other-initiation of repair are arguably fitted to the role of repair in fixing problems in perceiving and understanding. For instance, leaning forward makes it more likely you will better perceive what is said. Also, eyebrow movements are associated with thinking and "wanting to know" (Ekman and Friesen, 1975; Wierzbicka, 1999: 4).

\subsection{Conclusions}

We have presented the first findings of a cross-linguistic study of openclass other-initiation of repair. The findings are consistent with the view that other-initiation of repair is a system, linked into other systems of language such as a system of interjections, a system for formulating questions, and a system of visible behavior. We hope that our findings will be treated as suggestive hypotheses to be tested more systematically in subsequent research. 
In open-class other-initiation of repair, all spoken languages in our sample make use of a primary interjection strategy, in which a huh-like interjection is used to initiate repair. A notable finding was that the phonetic form of this interjection is strikingly similar across languages, suggesting that indexicaliconic motivation is one of the forces that shapes it. While we have considered possible motivations for this particular form-meaning mapping, further work is required to determine the extent to which the interjection takes a conventional form that fits the phonemic and prosodic system of a given language (as is known to be the case with interjections more generally). We would expect that natural motivation and conventionalization work together to shape the phonetic form of these items.

Most, but possibly not all, spoken languages, as well as the sign language in our sample, also have a question word strategy for open-class otherinitiation of repair. This may involve a word that means "what" all by itself, or it might (in addition) involve a more complex phrase, or a different question word, such as "how." The specifics of the question word strategy are, again, in part determined by the wider linguistic system. Here the constraints of the wider system are not just phonological, as with the interjection strategy, but also grammatical. The existence of more complex forms like "What's that?" and "What did you say?" in many of the languages that can use the question word on its own suggests a derivational relation between the single word strategy ("What?") and the more complex phrase ("What did you say?").

We hope here to have made a contribution to research on repair by putting the issue of linguistic diversity front and center. The field of research on language in social interaction is only just beginning to become truly comparative, as we broaden our scope to include not only the world's larger, better-known languages, but also the much more numerous, and arguably more representative, languages spoken by smaller populations in widely ranging cultural environments.

\section{REFERENCES}

Ameka, Felix K. (1992). Interjections: the universal yet neglected part of speech. Journal of Pragmatics 18(2-3): 101-118.

Árnason, Kristján (1998). Toward an analysis of Icelandic intonation. In Stefan Werner, ed., Nordic Prosody VII: Proceedings of the VIIth Conference, Joensuu 1996, pp. 49-62. Frankfurt am Main: Peter Lang.

Austin, J. L. (1962). How to Do Things with Words. Oxford: Clarendon Press.

Blevins, Juliette and Garrett, Andrew (1992). Ponapaean nasal substitution: new evidence for rhinoglottophilia. In Proceedings of the 18th Annual Meeting of the Berkeley Linguistics Society, pp. 2-21. Berkeley: Berkeley

Linguistics Society. 
Bloomfield, Leonard (1933). Language. New York: Holt.

Boyd, Robert, and Richerson, Peter J. (1985). Culture and the Evolutionary Process. University of Chicago Press.

Brown, Penelope (2010). Questions and their responses in Tzeltal. Journal of Pragmatics 42(10): 2627-2648. doi:16/j.pragma.2010.04.003.

Burling, Robbins (1993). Primate calls, human language, and nonverbal communication. Current Anthropology 34(1): 25-53.

Chafe, W. (1980). The Pear Stories: Cognitive, Cultural, and Linguistic Aspects of Narrative Production. Norwood, NJ: Ablex.

Clark, Herbert H. (1996). Using Language. Cambridge University Press.

Darwin, Charles (1872). The Expression of the Emotions in Man and Animals. London: J. Murray.

Dehé, Nicole (2009). An intonational grammar for Icelandic. Nordic Journal of Linguistics 32 (01): 5-34. doi:10.1017/S0332586509002029.

Drew, Paul (1997). "Open" class repair initiators in response to sequential sources of trouble in conversation. Journal of Pragmatics 28: 69-101.

Durham, William H. (1991). Coevolution: Genes, Culture, and Human Diversity. Stanford: Stanford University Press.

Egbert, Maria (1997). Some interactional achievements of other-initiated repair in multiperson conversation. Journal of Pragmatics 27: 611-634.

Egbert, Maria, Golato, Andrea, and Robinson, Jeffrey D. (2009). Repairing reference. In Conversation Analysis: Comparative Perspectives, ed. Jack Sidnell, pp. 104-132. Cambridge: Cambridge University Press.

Ekman, Paul (1979). About brow: emotional and conversational signals. In Human Ethology: Claims and Limits of a New Discipline, eds. Mario von Cranach, Klaus Foppa, Wolf Lepenies, and Detlev Ploog, pp. 169-202. Cambridge: Cambridge University Press.

Ekman, Paul, and Friesen, Wallace V. (1975). Unmasking the Face; a Guide to Recognizing Emotions from Facial Clues. Englewood Cliffs, N.J: Prentice-Hall.

Enfield, N. J., and Stivers, Tanya, eds. (2007). Person Reference in Interaction: Linguistic, Cultural, and Social Perspectives. Cambridge University Press.

Goffman, Erving (1978). Response cries. Language 54(4): 787-815.

Goodwin, Charles (1981). Conversational Organization: Interaction Between Speakers and Hearers. New York: Academic Press.

Gussenhoven, Carlos (2004). The Phonology of Tone and Intonation. Cambridge University Press.

Halliday, M. A. K., McIntosh, A., and Strevens, P., eds. (1964). The Linguistic Sciences and Language Teaching. London: Longman.

Heritage, John (1984). A change of state token and aspects of its sequential placement. In J. Maxwell Atkinson and John Heritage, eds., Structures of Social Action: Studies in Conversation Analysis, pp. 299-345. Cambridge University Press.

(1998). Oh-prefaced responses to inquiry. Language in Society 27(3): 291-334.

(2002). Oh-prefaced responses to assessments: a method of modifying agreement/ disagreement. In Cecilia E. Ford, Barbara A. Fox, and Sandra A. Thompson, eds., The Language of Turn and Sequence, pp. 196-224. Oxford/New York: Oxford University Press. 
Kendon, Adam (1967). Some functions of gaze-direction in social interaction. Acta Psychologica 26: 22-63.

Kim, Kyu-hyun (2001). Confirming intersubjectivity through retroactive elaboration: organization of phrasal units in other-initiated repair sequences in Korean conversation. In Margret Selting and Elizabeth Couper-Kuhlen, eds., Studies in Interactional Linguistics, pp. 345-372. Amsterdam: John Benjamins.

Kockelman, Paul (2003). The meanings of interjections in Q'eqchi' Maya: from emotive reaction to social and discursive action. Current Anthropology 44(4): 467-497.

Lambrecht, Knud (1994). Information Structure and Sentence Form: Topic, Focus, and the Mental Representations of Discourse Referents. Cambridge University Press.

Levelt, Willem J. M. (1983). Monitoring and self-repair in speech. Cognition 14: 41-104.

Levinson, Stephen C. (2010). Questions and responses in Yélî Dnye, the Papuan language of Rossel Island. Journal of Pragmatics 2010(42): 2741-2755. doi:10.1016/j.pragma.2010.04.009.

Lyons, John (1968). Introduction to Theoretical Linguistics. Cambridge University Press.

Manrique, Elizabeth. 2011. Other-repair initiators in Argentine Sign Language: handling seeing and understanding difficulties in face-to-face interaction. MA thesis, Radboud University Nijmegen, August 2011.

Matisoff, James A. (1975). Rhinoglottophilia: the mysterious connection between nasality and glottality. In Charles A. Ferguson, Larry M. Hyman, and John J. Ohala, eds., Nasálfest: Papers from a Symposium on Nasals and Nasalization, pp. 265-287. Stanford University.

(1994). Tone, intonation, and sound symbolism in Lahu: loading the syllable canon. In Leanne Hinton, Johanna Nichols, and John J. Ohala, eds., Sound Symbolism, pp. 115-129. Cambridge University Press.

Moerman, Michael (1977). The preference for self-correction in a Tai conversational corpus. Language 53(4): 872-882.

Ohala, John J. (1983). Cross-language use of pitch: an ethological view. Phonetica 40(1): 1-18.

(1984). An ethological perspective on common cross-language utilization of F0 of voice. Phonetica 41(1): 1-16.

Raymond, Geoffrey (2003). Grammar and social organization: yes/no interrogatives and the structure of responding. American Sociological Review 68(6): 939-967.

Richerson, Peter J., and Boyd, Robert (2005). Not by Genes Alone: How Culture Transformed Human Evolution. Chicago/London: University of Chicago Press.

Robinson, Jeffrey (2006). Managing trouble responsibility and relationships during conversational repair. Communication Monographs 73: 137-161. doi:10.1080/ 03637750600581206.

Rossano, Federico, Penelope Brown, and Stephen C. Levinson (2008). Gaze, questioning, and culture. In Jack Sidnell, ed., Conversation Analysis: Comparative Perspectives, pp. 187-249. Cambridge University Press.

Sacks, Harvey, and Schegloff, Emanuel A. (1979). Two preferences in the organization of reference to persons in conversation and their interaction. 
In George Psathas, ed., Everyday Language: Studies in Ethnomethodology, pp. 15-21. New York: Irvington Publishers.

Sapir, Edward (1921). Language. New York: Harcourt, Brace.

Schegloff, Emanuel A. (1992). Repair after next turn: the last structurally provided defense of intersubjectivity in conversation. The American Journal of Sociology 97(5): 1295-1345.

(2004). On dispensability. Research on Language and Social Interaction 37(2): 95-149.

(2006). Interaction: the infrastructure for social institutions, the natural ecological niche for language, and the arena in which culture is enacted. In Nick J. Enfield and Stephen C. Levinson, eds., Roots of Human Sociality: Culture, Cognition and Interaction, pp. 70-96. Oxford: Berg.

Schegloff, Emanuel A., Jefferson, Gail, and Sacks, Harvey (1977). the preference for self-correction in the organization of repair in conversation. Language 53(2): 361-382.

Seo, Mi-Suk and Irene Koshik (2010). A conversation analytic study of gestures that engender repair in ESL conversational tutoring. Journal of Pragmatics 42(8): 2219-2239. doi:16/j.pragma.2010.01.021.

Sidnell, Jack (2007). Repairing person reference in a small Caribbean community. In N. J. Enfield and Tanya Stivers, eds., Person Reference in Interaction: Linguistic, Cultural and Social Perspectives, pp. 281-308. Cambridge University Press.

(2010). Conversation Analysis: An Introduction. Chichester: Wiley-Blackwell.

Stivers, Tanya (2007). Alternative recognitionals in initial references to persons. In N. J. Enfield and Tanya Stivers, eds., Person Reference in Interaction: Linguistic, Cultural, and Social Perspectives, pp. 73-96. Cambridge University Press.

Talmy, Leonard (2000). Toward a Cognitive Semantics, vol. I: Concept Structuring Systems. Cambridge, MA: MIT Press.

de Vos, Connie, van der Kooij, Els, and Crasborn, Onno (2009). Mixed signals: combining linguistic and affective functions of eyebrows in questions in sign language of the Netherlands. Language and Speech 52(2-3): 315-339. doi:10.1177/0023830909103177.

Ward, Nigel (2006). Non-lexical conversational sounds in American English. Pragmatics and Cognition 14: 129-182. doi:10.1075/pc.14.1.08war.

Wierzbicka, Anna (1991). Cross-cultural Pragmatics: The Semantics of Human Interaction. Berlin/New York: Mouton de Gruyter.

(1999). Emotions Across Languages and Cultures: Diversity and Universals. Cambridge University Press.

Zhang, Wei (1999). Repair in Chinese Conversation. University of Hong Kong.

\section{NOTES}

1 Spoken texts such as recorded narratives and other kinds of monologue are now standardly used as sources for grammatical description, and while these will indeed contain cases of repair, those cases tend not to be a focus in linguistics (though they are sometimes a focus in psycholinguistics, e.g., Levelt 1983a inter alia). But even if one were to describe the cases of repair found in recorded monologues, one would 
not capture data on the kind of repair discussed in this chapter: other-initiated repair. A further reason why field linguists have overlooked the description of repair may be a kind of "invisibility" of repair in communication, due to its very ordinariness. When field linguists say Huh? and it works, this doesn't end up in their field notes. It is only when it doesn't work at first that it gets noted (as in Matisoff 1994: 117, 127n8).

2 The project is supported by funding from ERC project "Human Sociality and Systems of Language Use" and "Interactional Foundations of Language" Project, Language and Cognition Department, Max Planck Institute Nijmegen.

3 Previous work on other-initiation of repair has mostly been on English (Schegloff, Jefferson, and Sacks 1977; Drew 1997; Robinson 2006, inter alia; Egbert, Golato, and Robinson 2009; Robinson this volume), but has also featured work on a few other languages (Moerman 1977 on Tai; Egbert 1997 on German; Zhang 1999 on Mandarin Chinese; Kim 2001 on Korean; Sidnell 2007 on Caribbean English Creole, inter alia).

4 We use the term "open-class" here for consistency with the conversation analytic literature on repair (cf. Drew 1997; Sidnell 2010: 119ff), though we note a terminological clash. "Open-class" has long been in use as a technical term in linguistics, with a different meaning (Halliday, McIntosh, and Strevens 1964: 22; Lyons 1968: 436; Talmy 2000: I: 22). In the lexicon, an open-class item is a member of a set that is large and in principle not limited - e.g., nouns and verbs in English - by contrast with closed-class items such as grammatical morphemes that mark case, agreement, etc. By contrast, with reference to other-initiation of repair, "open-class" does not refer to a class, but to a certain scope of focus in information structure terms (cf. e.g., Chafe, 1980 and Lambrecht, 1994): an open-class repair initiator has something like "unrestricted focus" (Lambrecht 1994: 233ff), that is, focus on the whole of the prior utterance. This is in contrast with other kinds of other-initiators of repair that have restricted focus on some sub-part of the relevant turn or clause (e.g., "Who?", "Where?", "Which one?", "He did what?"). For other-initiation of repair, when we say "open-class" in this chapter, we do not mean this in the linguistics sense of the word, but rather in the technical sense of "unrestricted focus."

5 Jeff Robinson notes some differences between English What? and Huh? in personal communication (cf. Robinson 2006: 142). Based on impressions from a large collection of the two forms in English, Robinson suggests that Huh? may be more often dealing with problems of hearing and understanding, while What? may be more likely to extend into dealing with problems of alignment/agreement/affiliation. He notes that What? can show greater formal variation as well (e.g., greater variety of prosodic variants). See Robinson (2006) for discussion of other distinctions in the English system for open-class other-initiation of repair; also Egbert, Golato and Robinson (2009), Robinson (this volume).

6 The data are all recordings of maximally informal interaction, typically between people who know each other well (family, friends, neighbors). None of the data are from institutional contexts. This means that we do not have the range of data necessary for looking at distinctions in formality or politeness. In most cases, the data were video-recorded, except in the cases of Icelandic and Hungarian, which were audio-only. In most cases, the data were collected in fieldwork by the researcher (with funding from MPI Nijmegen and ERC HSSLU project). Data 
collection for $¥ \bar{A}$ khoe Haillom and Yurakaré was funded by the DoBeS program of the Volkswagen Foundation. We thank the University of Iceland and the Árni Magnússon Institute for Icelandic Studies for access to conversations in ÍS-TAL, the Corpus of Spoken Icelandic (Íslenskur Talmálsbanki), and Monica Turk for giving us access to her Beijing Mandarin data.

7 The forms in this column are representative tokens observed in our data sample. There is no implication that these are the only forms found in the language. A closed-mouth version [hm] was observed in the data for some of the languages, and therefore included in the table. It is likely that it is available in more languages and would surface in larger data samples.

8 We list LSA (Argentine Sign Language) for completeness in this table but we cannot give entries for the rightmost two slots because this table lists only vocal sounds. See section 3.4 for discussion of the situation in LSA (see also Manrique, 2011).

$9 \mathrm{He}$ was, however, equivocal on the non-word status of these forms. In the same paragraph he stated that "the sound that covers any particular non-word can stand by itself, is standardized within a given language community, and varies from one language community to another, in each case like full-fledged words" (1978: 810).

10 It is not unimaginable that the forms are borrowed across the languages, but this seems highly unlikely. While it is true that interjections, being free-standing units, may be more likely than many other elements of language to be borrowed across languages, due to their salience and their lack of grammar-specific contextual constraints, this would not be enough to account for the uncanny similarity across languages of such extreme typological and geographical diversity as those in our sample.

11 Perhaps when Levelt (1983b) refers to $u h / u m$ as a "symptom" he means that it is motivated by Darwin's third principle, that is, these interjections are comparable to "a start from a sudden noise" (Darwin 1872: 9).

12 Árnason (1998) notes that questions ending in an L\% tone are "simple requests for information" while questions ending in a $\mathrm{H} \%$ tone (less frequent) involve "a friendly suggestion by speaker A" (p. 56).

13 Human communicative systems for interaction include the full gamut of our inherited resources. Humans have a unique system of dual inheritance (Durham 1991; Boyd and Richerson 1985; Richerson and Boyd 2005), which means that a child inherits both a set of natural affordances grounded in phylogenetic history and a set of cultural affordances grounded in cultural history. In human communicative interaction we see these two sources grafted together.

14 In the repeated version of $\mathrm{T}-1$, the speaker omits the address form mama (mama and papa are commonly used to address children in Cha'palaa, although they are more literally words referring to parents).

15 It can, however, function as a restricted-focus repair initiator picking out a singular, nominally expressed referent in nominative or accusative case, usually neuter.

16 The apparent contrast between the verbal and gestural messages can be resolved in the following way: the room in which BSR's grandchildren spend most of their time is vertically above him (licensing the pointing gesture), but to his left, thus on his "downhill" side (justifying moba).

17 Jeff Robinson (personal communication) confirms this for English based on a large collection. 